Revista Água Viva

\title{
O LUGAR DO CORPO FEMININO EM NARRATIVAS E CANÇÕES CONTEMPORÂNEAS BRASILEIRAS*
}

\section{THE PLACE OF THE FEMALE BODY IN BRAZILIAN CONTEMPORARY NARRATIVES AND SONGS}

\author{
Amanda Maria Garcia Holgado de Oliveira ${ }^{1}$
}

Recebido em: 04 jul. 2019.

Aceito em: 19 dez. 2019.

DOI 10.26512/aguaviva.v5i3.25755

\begin{abstract}
Quero pedir desculpa a todas as mulheres
Que descrevi como bonitas

Antes de dizer inteligentes ou corajosas.
\end{abstract}

Rupi Kaur

RESUMO: Pensar no corpo enquanto instância de enunciado e manifestação de privilégios, resistência, identificações e enfrentamento é o propósito deste artigo. O corpo é visto e confrontado por representar características aceitas ou negadas por um senso comum, o que gera estigmas e preconceitos. Este artigo traz compositoras e autoras da música e literatura brasileiras contemporâneas que apontam o confronto do corpo através das determinações sociais impostas a ele. Serão analisadas na obra musical de Karina Buhr, canções do álbum Selvática, de Karol Conka, canções do álbum Batuk Freak. Na literatura, o romance Coisas que os homens não entendem de Elvira Vigna e o conto "Isaltina Campo Belo" de Conceição Evaristo. Os discursos são analisados considerando um potencial afirmativo das obras sobre as práticas feministas enquanto descolonizadoras, dialogando com as teorias acerca do corpo de Judith Butler, Guacira Lopes Louro e Lélia Gonzales.

Palavras-chave: Corpo. Canções. Narrativas de autoria feminina. Feminismo.

ABSTRACT: Thinking about the body as an instance of enunciation and manifestation of privileges, resistance, identifications and confrontation is the purpose of this article. The body is seen and confronted by representing characteristics accepted or denied by a common sense, which generates stigmas and prejudice. This article brings composers and authors of contemporary Brazilian music and literature that point to the confrontation of the body through the social determinations imposed on it. It will be analyzed in the musical work of Karina Buhr, songs from the album Selvática, Carol Conka, songs from the album Batuk Freak. In literature, the novel Coisas que os homens não entendem by Elvira Vigna and the short story "Isaltina Campo Belo" by Conceição Evaristo. Considering that the works under analysis have an

\footnotetext{
${ }^{1}$ Mestranda em Literatura na Universidade de Brasília - UnB. E-mail: amanda.holgado@gmail.com

* Parte deste texto (com alterações) foi publicado no blog do Grupo de Estudos em Literatura Brasileira Contemporânea, em outubro de 2017. Disponível em: <gelbcunb.blogspot.com.br/2017/10>
} 
affirmative potential about feminist practices as decolonizers, the analysis will dialogue with theories about the body of Judith Butler, Guacira Lopes Louro and Lélia Gonzales.

Keywords: Body; Music; Literature of female authorship; Feminism.

Ao ser atribuído ao corpo uma pessoalidade, "a própria categoria sexual parece pressupor uma generalização do 'corpo' que preexiste à aquisição de seu significado sexuado", como afirma Butler (2017, p. 223), ou seja, recai sobre ele uma fonte cultural externa. Este é definido dialogicamente, desde um primeiro contato, um corpo de homem ou um corpo de mulher. A sua materialização é base da diferenciação da relação biológica que se deu entre este par, divisão que estruturou uma concepção binária de identidade dentro do meio social, gerando, historicamente, divisões de afazeres, esferas da vida, acesso a direitos e subordinação.

Esse conceito definido e demarcado em relação à mulher, partindo das estruturas patriarcais que a subordinaram em função de seu corpo, materializando-o, estende-se para diversas esferas. Demandas externas foram exigidas e definiu-se um padrão de beleza que parte da exclusão: “os grupos sociais que ocupam posições centrais, 'normais' (de gênero, de sexualidade, de raça, de classe etc) têm a possibilidade não apenas de representar a si mesmos, mas também de representar os outros" (LOURO, 2007, p. 16), apresentando, como padrão, a sua própria estética, estabelecendo relações de poder. Estas podem ser vistas sobre os corpos negros, transexuais/transgêneros ou em pessoas com deficiência, por exemplo.

Na mídia, em propagandas ou revistas, essas diferenças entre corpos não existem, embora isso venha mudando, por exemplo, em propagandas, principalmente nas veiculadas na Internet, de produtos de beleza que atendem a diversos públicos, mesmo sabendo-se que "as representações populares podem utilizar convincentemente a retórica e o simbolismo, falando em alcançar poderes e liberdade pessoal, em "ter tudo"” e desta forma mantendo um "ideal feminino de dependência" (BORDO, 1997), é relevante pensar em novas abordagens de representação.

As representações vêm mudando também na arte, como no caso dos romances de Elvira Vigna, que apresentam comportamentos não convencionais em suas personagens. Em Coisas que os homens não entendem, a protagonista, Nita, constrói e desconstrói atitudes consideradas e estabelecidas socialmente - típicas femininas e traz em si uma força, uma identidade que escapa às representações usualmente feita sobre mulheres. É uma personagem 
que anda pela cidade sozinha, que viaja, se narra como a primeira mulher a trabalhar em um jornal em que só havia trabalhado até então homens.

Outra autora que apresenta em suas obras a desconstrução de personagens estigmatizadas é Conceição Evaristo, que explora as vivências e experiências de mulheres negras, ou como a própria autora descreve, as escrevivências. O livro de contos Insubmissas lágrimas de mulheres explicita as bonitas formas de resistências encontradas pelas personagens. O conto "Isaltina Campo Belo" é um desses e sua protagonista tem em si variadas possibilidades de opressões que um corpo pode sofrer.

No espaço da música, as representações da mulher aparecem de maneira emancipatória, como nas canções das cantoras-compositoras Karina Buhr e Karol Conka, onde afirmam o potencial do corpo feminino não como objeto, mas como espaço de construção de narrativas identitárias definidas de acordo com seus próprios valores e não com os valores machistas e patriarcais que subjugam, padronizam e objetificam os corpos das mulheres.

Além disso, movimentos alinhados ao feminismo (em suas diversas facetas), que emergiram depois de muitos estudos e militâncias, vêm surgindo para contrapor a essas convenções que têm vigorado. Nos últimos anos, com a popularização das redes sociais, a ideia de empoderamento feminino se fortaleceu e a circulação dessa ideia tem colaborado, em alguma medida, para um despertar de consciência dessa regulação dos corpos e reconhecimento da beleza na diversidade, além de se repensar esses valores socialmente construídos. Portanto, se considerar e reconhecer as estruturas que fundamentaram tais questões contribui para esse fortalecimento e despertar.

\section{Não conformações: o corpo em devir nas narrativas}

O corpo enquanto meio de transformação aparece em narrativas contemporâneas brasileiras que de alguma forma não atendem aos padrões estabelecidos socialmente, onde as personagens se colocam em processos de reconhecimento e aceitação desse corpo no mundo.

No romance Coisas que os homens não entendem (2002), de Elvira Vigna, Nita, protagonista e narradora da obra, conta que foi uma jovem jornalista da sessão policial, onde somente trabalhavam homens. Quando mais velha, fotógrafa, independente, uma mulher em trânsitos, viveu diversas relações - homo e heterossexuais. Nita se apresenta como uma mulher consciente de seu corpo e sua história, mas em sutis brechas deixa escapar uma inconformidade com sua figura: "E em uma das janelas, por trás de uma cortina de flores, alguém dizendo: tem 
uma mulher estranhíssima parada no portão" (Vigna, 2002, p. 22); e com seu corpo: "Eu sempre tive inveja das pessoas que se sentem em casa, seja no assento de um carro, seja em seus próprios quadris" (Vigna, 2002, p. 55) e também os conflitos que carrega em si, inclusive um fato importante na trama é que a narradora conta, também parecendo que "deixou escapar", que foi abusada sexualmente pelo seu chefe no jornal e pai de seus amigos.

As relações que Nita expõe de maneira muito particular compõem uma espécie de quadro nublado que de alguma forma fomentam a ideia da pressão que os corpos sofrem, muitas vezes, devido à naturalidade designada, que acaba por definir uma estética única, jogando para a margem o que não é concebido como "normal”. Esse poder lança sobre o indivíduo um fardo que interfere nas esferas pública e privada. Até o fato de apresentar o abuso que sofreu como algo que "não foi bem assim", explicita essa normalização, mesmo com uma mulher que se coloca em uma posição de privilégio intelectual, viajada, conhecedora de outras culturas, "Nós, os que sabíamos tanto, não sabíamos que o Brasil tinha mudado e que não precisava mais de nós" (Vigna, 2002, p. 131).

Um corpo que não reconhece seu valor, ou não se vê representado, acha-se sem forças para lutar e recorrer a seus direitos. Importante destacar também que nesse exemplo, Nita, foge das personagens tipicamente femininas, pois apresenta muitas contradições em suas falas, atos, e ao que parece não busca alcançar um ideal esperado socialmente, nem quanto a seu corpo, nem nos modos de vida - vive romances errantes, sua profissão, fotógrafa, não tão convencional para mulheres, possibilitando então uma leitura que não atende aos ditames patriarcais.

Outro aspecto que se faz presente ao se pensar em ideais coercitivos é de como as minorias étnicas experienciam essa construção excludente, já que seus corpos jamais atenderão à universalização.

A respeito do corpo da mulher negra, por exemplo, há uma mitificação que projeta sobre ele determinações referentes à prestação de bens e serviços - incluindo sexuais - caracterizadas pela função da escrava no sistema produtivo do processo escravista do contexto brasileiro, como afirma Lélia Gonzales (1986).

As mulheres negras eram chamadas de mucamas. A partir dessa ideia, determinou-se que a mulher negra poderia ser vista sob três perspectivas: como a mulata, a doméstica, ou sob a noção da mãe preta. Gonzales estabelece essa relação com o conto de fadas, através do rito carnavalesco, "é nesse instante que a mulher negra transforma-se única e exclusivamente na rainha [...]. Ali, ela perde seu anonimato e se transfigura na Cinderela do asfalto, adorada, desejada, devorada pelo olhar dos príncipes altos e loiros, vindos de terras distantes só para vê- 
la” (1986, p. 228), já em seu cotidiano caracterizada agressivamente sempre como doméstica, considerada como o lado oposto da exaltação.

As construções dessas divisões geram profundas marcas sociais que se mantém por gerações, e a permanência desses estigmas contribui para a naturalização de pensamentos dominantes graves que determinam essas disparidades e desigualdades abordadas aqui. Essas perspectivas confirmam a ideia da presença suprimida historicamente da mulher do contexto social, além de colocada como instrumento, afônica e submissa, e seu corpo como o atributo das realizações domésticas, dos afetos e dos desejos de outrem.

Uma personagem que transfigura essas determinações, apesar de ser brutalmente marcada pelo preconceito em torno de seu corpo, gênero, raça e opção sexual é Isaltina, do conto Isaltina Campo Belo, de Conceição Evaristo, publicado no livro Insubmissas lágrimas de mulheres (2011). A primeira relação que a personagem coloca quanto ao corpo é que quando criança não se reconhecia como mulher, ela se sentia um menino e se impressionava com a não percepção dos adultos sobre o fato. Na adolescência esse estranhamento aumenta, pois tudo que via ou aprendia sobre o corpo da mulher e do homem não condizia com o que percebia em si mesma:

descobrimos, na rua e nos livros, tudo sobre o corpo da mulher e do homem. Sobre beijos e afagos dos homens para com as mulheres. Lembro-me que fui invadida por certo sentimento, que não sei explicar até hoje, uma sensação de estar fora de lugar. Eu via e sentia meu corpo parecer com o de minha irmã e se diferenciar do porte de meu irmão (EVARISTO, 2011, p. 53).

Ao crescer, Isaltina, que morava no interior, foi estudar enfermagem na cidade. No hospital que trabalha conhece um rapaz, com quem começa um namoro que não se desenvolve, porém continuam amigos. Esse amigo afirmava que ela "deveria gostar muito e muito de homem, apenas não sabia", marcando a relação de poder e afetação do homem sobre a mulher e fixando a heterossexualidade compulsória, principalmente pelo fato de ela ser negra, devido à “objetificação e hipersexualização da mulher negra”, como coloca Ana Carolina Quiangala (2016).

O rapaz a convida para uma festa na casa dele com mais cinco amigos, acontece, então, um estupro coletivo e corretivo, eles diziam que estavam ensinando-a a ser mulher. Isaltina engravida, porém só se dá conta no sétimo mês - nunca se sentira num corpo feminino, com suas regras e costumes -, ela tem a criança. No primeiro ano de escola de sua filha, ao levá-la na aula se apaixona pela professora. É neste momento que, finalmente, reconhece sua identidade 
de gênero: "E foi então que eu me entendi mulher, igual a todas e diferente de todas que ali estavam" (EVARISTO, 2011, p. 58).

Neste caso, o conflito da personagem se dá pelo não reconhecimento de seu corpo em torno de sua identidade de gênero, quando criança, e de sua sexualidade ao se reconhecer diante de uma possibilidade amorosa. O meio externo gera conflitos devido também a sua raça.

O conto é muito poético, por vezes dolorido, ao mostrar o processo de conscientização e compreensão da identidade da personagem. Um aspecto muito interessante é a perspectiva da criança, que não se reconhece naquele corpo e não entende como os adultos não percebem que ela "não é o que parece ser". Essa criança apresentava uma visão desprendida de conceitos, julgamentos e não preconceituosa, sendo esta uma visão construída social, histórica e culturalmente.

Tanto no caso de Nita, do romance Coisas que os homens não entendem, quanto no de Isaltina, em "Isaltina Campo Belo", o corpo apresenta a relação de um não-lugar enquanto espaço impossibilitado de manifestação das suas potencialidades conforme o meio externo espera, há sempre um desconforto, uma incongruência na voz dessas personagens em relação ao próprio corpo. Porém esses corpos, ambos violentados apresentam, de forma diferente, a resistência e a capacidade de transformação.

Nita, que conta sobre o assédio que sofreu de forma amena, acaba por matar o filho do seu agressor, apresentando também como algo feito espontaneamente, por mera fatalidade. No caso de Isaltina, que conta de forma aberta o assédio sofrido, recebe a filha fruto desse abuso e credita a ela a alegria de ter conhecido a sua companheira, a professora da escola, com quem pode entender a sua opção sexual e se casou.

\section{Re-existir: a experiência do corpo em canções}

Complexas relações e multifacetados discursos se entremeiam para buscar a melhor forma de contemplar e compreender os arranjos sociais, que precisam ser vistos pelos diversos aspectos que cerceiam o status quo, como as diversas teorias feministas, e como consequência, a materialização desses discursos pode ser vista através da arte, no caso das canções também se identificam vozes silenciadas e trazem à luz a força no reconhecimento de si e de seus corpos.

Karina Buhr, em Selvática (2015), expressa em suas composições o resgate do poder da mulher, enquanto guerreiras de histórias de séculos atrás, e denuncia esse complexo enquadramento sobre o "jeito" de estar no mundo em que mulheres foram colocadas. Em $E u$ 
sou um monstro, por exemplo, Buhr diz "Hoje eu não quero falar de beleza / Ouvir você me chamar de princesa / Eu sou um monstro", subvertendo essa ideia de perfeição destinada à mulher, inspirada nos contos de fadas clássicos, que direcionam o destino único da princesa em função do príncipe.

Um outro aspecto é o da afirmação "não quero falar de beleza", ideia da preocupação estética, por muito tempo difundida somente para mulheres. Desta forma, a compositora expõe o contraponto e se coloca como um monstro, rompendo esse ideal de beleza e também classificações como meiguice, delicadeza e subordinação, as quais sempre foram destinadas socialmente a uma característica intrínseca da mulher, mais especificamente à mulher branca. Essa figura mítica do monstro pretende suspender as determinações históricas.

Na composição, homônima ao álbum, "Selvática", trabalha-se o resgate do corpo da mulher guerreira, corpo de luta, contrapondo a ideia de corpo feminino fragilizado e indefeso, também mais específico para o corpo da mulher branca, e se concretiza a figura do monstro, como se apresenta no trecho:

Mulheres, conforme a espécie, na guerra esbravejam a dor / Da terra em uivos lhe crescem pupilas ruivas, uvas bacantes / Semeadas, oliveiras palestinas suculentas / Avisam: Já não há quem possa! / Chifre de marfim nascem devagar a empurrar / Entremeando os cabelos / Afiam-se - dentes - pontasde-diamantes / Estraçalhadores fulminantes de pecadoras maçãs. / Vãs as imagens delas conforme a sua semelhança/ bailarão lança e festança / Extirparão o sumo da memória criminosa / Refarão a história e a prosa de tuas eternas / Inquisições de fogueiras em beiras de abismos. (BUHR, 2015)

E aponta a ideia da possibilidade da mulher ser guerreira, viril, característica destinada socialmente a uma essência masculina, inclusive dicionarizada. Em Aulete digital, aparecem as seguintes definições para o termo viril: “1. Característico do homem, do varão, ou que se refere a ele (trabalho viril); másculo; varonil. 2. Que possui energia e vigor (atitude viril)".

Essa atitude viril, mítica e monstruosa pretende refutar os símbolos do processo histórico sobre a mulher, presentes no inconsciente coletivo, ao se dizer "pecadoras maçãs" ou ao considerar as bruxas queimadas em fogueiras, a fim de refazê-los, desmistificá-los.

Karol Conka também tem feito um trabalho na música que expressa abertamente a beleza, a força e a liberdade das mulheres. A cantora e compositora se coloca no lugar experiencial das suas canções, como mulher, negra e periférica consciente do seu corpo e da beleza para além das determinações sociais, como se pode ver em Você não vai, do álbum Batuk Freak (2013), que diz: "Você parece que esquece que eu não uso estepe 
/ Meu poder é black / Te provo tudo isso no rap", marcando também a presença num espaço marcadamente masculino como o rap.

Em Gandaia, também de Batuk Freak (2013), a compositora canta o ambiente de uma festa com as amigas que "vão se jogar", com plena consciência da liberdade de seus corpos sem deixar espaço para abusos devido a aproveitar a noite: "Bom de mais é desse jeito / Vai com calma rapaz, mais respeito / Dá dez passos pra trás fica ai mesmo / é bom ter disciplina se quiser sair ileso".

Em entrevista ao site Huffpost, Conka explica o que considera ao tratar desses temas em suas letras:

É muito importante ter esse tipo de música porque existem muitas meninas frustradas precisando de uma palavra de conforto. E a mídia e a sociedade reforçam esse padrão e criam pessoas frustradas. Eu já passei por isso. Quando eu era mais nova, me sentia muito mal por ser diferente. Por isso, resolvi escrever músicas que ajudassem outras meninas que sentiam a mesma coisa que eu. Acredito que quando a gente ouve uma música com palavra de conforto, de alguém que te entende, a gente pode se sentir melhor (CONKA, 2017).

Esses exemplos refletem uma autoria que resiste ao que é imposto pelas condições em que esses corpos foram submetidos, aspirando a um movimento de mudança perante à sociedade contemporânea, e indicam diversidade nessas vozes, na linguagem empregada, na forma de suas composições, estilos musicais e lugares de fala. São corpos que atendem ou não a padrões estabelecidos socialmente e em conformidade com essa divisão binária sexista. As personagens estão em processos de reconhecimento e aceitação desse corpo no mundo.

Esses são poucos exemplos dentre diversos que possam suscitar tal tema ou que possam representar outros tipos de debate acerca do corpo, como o corpo com deficiência, que também é colocado num não-lugar de reconhecimento social.

Além do mais, é representativo o fato de serem escritoras mulheres, tendo em vista que esta tarefa foi socialmente destinada a homens, quando feita por mulheres se torna resistência, o que se observa no trecho que segue abaixo da chicana Glória Anzaldúa (2000):

Por que sou levada a escrever? Porque a escrita me salva da complacência que me amedronta. Porque não tenho escolha. Porque devo manter vivo o espírito de minha revolta e a mim mesma também. Porque o mundo que crio na escrita compensa o que o mundo real não me dá. No escrever coloco ordem no mundo, coloco nele uma alça para poder segurá-lo. Escrevo porque a vida não aplaca meus apetites e minha fome. Escrevo para registrar o que os outros apagam quando falo, para reescrever as histórias mal escritas sobre mim, sobre 
você. Para me tornar mais íntima comigo mesma e consigo. Para me descobrir, preservar-me, construir-me, alcançar autonomia. Para desfazer os mitos de que sou uma profetisa louca ou uma pobre alma sofredora. Para me convencer de que tenho valor e que o que tenho para dizer não é um monte de merda. Para mostrar que eu posso e que eu escreverei, sem me importar com as advertências contrárias. Escreverei sobre o não dito, sem me importar com o suspiro de ultraje do censor e da audiência. Finalmente, escrevo porque tenho medo de escrever, mas tenho um medo maior de não escrever (ANZALDÚA, Glória, 2000, p. 232).

Este trecho do ensaio de Anzaldúa apresenta a relevância da autoria feminina. E tornase ainda mais significativa quando a escrita reflete sobre os processos de condicionamento e regulação dos corpos enquanto locais de manifestação desse processo colonizador, ressignificando esse espaço.

O que ocorre também, como é o caso das obras aqui discutidas, que questionam a existência da ditatura da beleza, da magreza e da perfeição, que atendem às exigências da sociedade pós-moderna, pois, como coloca Susan Bordo (1997, p. 23) “essa construção está sempre homogeneizando e normalizando, tentando suprimir as diferenças de raça, classe e outras, insistindo para que todas as mulheres aspirem a um ideal coercitivo, padronizado".

Desta forma, entende-se o corpo como um lugar no mundo, dual e complexo, que antecipa sua chegada, classifica o ser, inscreve acontecimentos sociais e culturais, porém não pode ser determinado, pois o corpo é em si uma força, de escolhas e resistências. Deixar que o corpo seja determinado, regulado, condenado ou negado, assim como suas práticas, necessidades, desejos e prazeres, e categorizá-lo hegemonicamente como único aceitável segundo um padrão, é cristalização e redução do sujeito, além de que um sujeito é "engendrado" e constituído em um gênero - antecipado pelo corpo - "não apenas pela diferença sexual, e sim por meio de códigos linguísticos e representações culturais" (LAURETIS, 1994) e também pelas relações de raça e classe. Devido a isso, personalizar o sujeito é identificá-lo como singular, é desconstruir a totalidade em que foi antecipadamente colocado.

Os discursos dados nos exemplos das músicas e das personagens literárias se colocam no lugar de reconhecimento de um corpo posto em subordinação e são as próprias vozes desses corpos que se representam, a importância disso é entender a "reinvindicação de seus corpos como lugares de significado e valor" (SCHMIDT, 1999) e não só sendo colocados a prova por olhares deterministas e machistas hegemônicos. Para tanto, destaca-se assim a relevância da discussão desse tema e permanência do reconhecimento da diversidade corporal nas variadas formas de arte. 
Além do mais, considerar o corpo como uma prática decolonial, envolve pensá-lo em outra lógica de funcionamento e pensar as relações dialéticas entre corpo e mundo e mantê-lo sempre em diálogo com o mundo fora dele, o que implica entender que tudo está em constante mudança, as perspectivas não podem ser fixas e absolutas, como coloca Hooks (2013), e também passar a compreender o corpo em sua integridade - mente, corpo e espírito - dessa forma, a possibilidade de consciência crítica que realmente transgrida aos meios colonizados e se coloquem em expansão, livres de tabus, preconceitos, determinismos e verdades únicas.

\section{REFERÊNCIAS}

ANZALDÚA, Glória. Falando em línguas: uma carta para as mulheres escritoras do terceiro mundo. Estudos Feministas. Ano 8, p. 229-236, 2000. Disponível em: <https://periodicos.ufsc.br/index.php/ref/article/view/9880/9106> Acesso em: 17 de mar. 2018.

AULETE, Caldas. Dicionário Online. 2018. Disponível em: <www.aulete.com.br/> Acesso em 20 mar. 2018.

BORDO, Susan. O corpo e a reprodução da feminidade: uma apropriação feminista de Foucault. In: JAGGAR, Alison; BORDO, Susan (Editoras). Gênero, corpo, conhecimento. Tradução: FREITAS, Britta Lemos de. Rio de Janeiro: Record / Rosa dos Tempos, p.19 - 41, 1997.

BUHR, Karina. Selvática; Eu sou um monstro. In: BURH, Karina. Selvática. São Paulo: YB Music, 2015.

BUTLER, Judith. Problemas de gênero: feminismo e subversão da identidade. Tradução: AGUIAR, Renato. Rio de Janeiro: Civilização Brasileira, 2017.

CONKA, Karol. Gandaia; Você não vai. In: KAROL, Conka. Batuk Freak. Rio de Janeiro: Deckdisc, 2013.

CONKA, Karol. Karol Conka fala sobre racismo, empoderamento da mulher negra e machismo dentro do rap nacional. GENNARI, Ana Júlia. Huffpost. Janeiro, 2017, 2018. Disponível em: <www.huffpostbrasil.com/2016/03/08/karol-conka-fala-sobre-racismoempoderamento-da-mulher-negra-e_a_21686477/> Acesso em 20 mar. 2018.

EVARISTO, Conceição. Isaltina Campo Belo. In: Insubmissas lágrimas de mulheres. Belo Horizonte: Nandyala, 2011.

GONZALES, Lélia. Racismo e sexismo na cultura brasileira. Revista Ciências Sociais Hoje, Anpocs, p. 223-244, 1984. Disponível em: 
<file://C:/Users/Configurador/Downloads/RACISMO\%20E\%20SEXISMO\%20NA\%20CUL TURA\%20BRASILEIRA.pdf >. Acesso em: 19 mar. 2018.

HOOKS, Bell. Ensinando a transgredir: a educação como prática da liberdade. Tradução de Marcelo Brandão Cipolla. São Paulo: Ed. WMF, 2013.

LAURETIS, Teresa de. A tecnologia do gênero. Tradução de Susana Borneo Funck. In: HOLLANDA, Heloísa Buarque de (org.). Tendências e impasses: o feminismo como crítica da cultura. Rio de Janeiro: Rocco, 1994.

LOURO, Guacira Lopes. Pedagogias da sexualidade. In: LOURO, Guacira Lopes (org.) 0 corpo educado: pedagogias da sexualidade. Belo Horizonte: Autêntica, 2007.

QUIANGALA, Ana Caroline. A Identidade de Gênero Racializada em Isaltina Campo Belo (Conceição Evaristo). Revista Intercâmbio dos Congressos Internacionais de Humanidades, Brasília, n. 6, p. 475-485, 2016. Disponível em: < https://bit.ly/2qygrYi > Acesso em: 20 mar. 2018.

SCHMIDT, Simone Pereira. Falar ou falar-se: o corpo no [do] texto pós-moderno. In: SILVA, Alcione Leite da; LAGO, Mara Coelho de Souza; RAMOS, Tânia Regina Oliveira. (org.) Falas de Gênero: teorias, análises, leituras. Florianópolis: Editora Mulheres, 1999.

VIGNA, Elvira. Coisas que os homens não entendem. São Paulo: Companhia das Letras, 2002. 